\title{
Environmental impacts of thermal emissions to freshwater: spatially explicit fate and effect modeling for life cycle assessment and water footprinting
}

\author{
Stephan Pfister ${ }^{1,2} \cdot$ Sangwon Suh ${ }^{2}$
}

Received: 12 November 2014 / Accepted: 16 April 2015 /Published online: 6 May 2015

(C) Springer-Verlag Berlin Heidelberg 2015

\begin{abstract}
Purpose Thermal emissions from electric power generation plants can lead to environmental impacts. However, such emissions have neither been comprehensively integrated in life cycle assessment (LCA), a method to quantify environmental impacts throughout the life cycle of a product, nor in water footprinting. This study presents a spatially explicit $(0.5$ arc degree resolution) fate and effect model for assessing the impact of thermal emissions from power production in the USA on freshwater ecosystems.

Methods We developed a two-step regionalized fate model to capture short-range and long-range thermal effects. Effect factors were derived as a function of ambient temperature and used in conjunction with the fate factor to calculate the impacts. The impacts are measured as the potentially disappeared fraction (PDF) of species in the affected freshwater ecosystem volume over time.

Results and discussion The long-range freshwater ecosystem impacts are dependent on the distance to sea as well as the ambient temperature, while the short-range effects are mainly influenced by the induced temperature change at the point of mixing. Our analysis showed that $95 \%$ of the modeled grid
\end{abstract}

Responsible editor: Masaharu Motoshita

Electronic supplementary material The online version of this article (doi:10.1007/s11367-015-0893-8) contains supplementary material, which is available to authorized users.

Stephan Pfister

pfister@ifu.baug.ethz.ch

1 Institute of Environmental Engineering, ETH Zurich, John-von-Neumann-Weg 9, 8093 Zurich, Switzerland

2 Bren School of Environment, University of California, Santa Barbara, CA, USA cells in the USA have an impact of $2.5 \times 10^{-6}$ to $2.5 \times$ $10^{-4} \mathrm{PDF} \mathrm{m}^{3}$ years per MJ emitted heat. For natural gas power production, thermal pollution can have a significant contribution to total freshwater ecosystem quality.

Conclusions This study shows that thermal effects can be calculated on a spatially explicit level based on background data. It reveals the variability within a large region of the world, covering various geographic regions, and therefore helps generalizing the results for other regions.

Keywords Heat impacts · Inventory · Power production · Thermal emissions $\cdot$ Water footprint

\section{Introduction}

The environmental impact of industrial operations is a topic that is increasingly being studied. Quantitative assessments of greenhouse gases (GHGs) and other emissions have been performed using methods such as life cycle assessment (LCA, ISO 2006) and carbon footprints (Finkbeiner 2009; ISO 14067 2013). While well-established indicators exist for quantifying many impact categories such as global warming and fossil resource consumption, internationally accepted metrics for impact assessment on water ecosystems are still limited (JRC 2011). These metrics are also subject to high spatial variability (Kounina et al. 2013). The impacts of substance emissions to water have been characterized by many sophisticated models (JRC 2011). However, there is still a lack of proper assessment of heat releases and anti-fouling chemicals that are encountered especially in thermal power production. Impact assessment of thermal emissions from power production is only available for a specific case study, whereby a detailed model was used to calculate excess heat concentrations (i.e., temperatures) along the course of a river for a 
specific nuclear power plant situated in Switzerland (Verones et al. 2010). In order to perform a rigorous assessment of heat releases, more widely applicable characterization factors $(\mathrm{CFs})$ must be calculated to enable practitioners to carry out impact assessment of all emissions. It is important to note that such a CF is very site-dependent since natural water temperature, distance to sea, and river flow are key influencing factors (Verones et al. 2010). A global water temperature model has recently been published (van Vliet et al. 2012), but the results are only available for a few watersheds.

We chose case studies of thermal power generation using coal and conventional natural gas to investigate the applicability of the proposed methodology. Freshwater heat releases from cooling systems are just one of the environmental impacts of thermal power generation. This is why we also modeled other freshwater impacts, allowing us to relate the relevance of thermal emissions, as well as that of the supply chain of power production systems. We provide water footprint results that are in line with the ISO 14046 standard (ISO 2014). Currently, no study provides fate and effect models for assessing the impacts of thermal emissions on a spatially explicit level. Here, we also evaluate the water consumption impacts due to thermal power production. This is important since most options other than once-through for cooling in large-scale plants lead to high water consumption (evaporation) and therefore reduced water availability downstream. In a similar context, a recent study analyzed the water availability for power production, specifically examining the differences between cooling tower and once-through cooling systems, but they did so from a regional ecosystem service perspective (Miara et al. 2013).

The main goal of this work is to develop an impact assessment method with the corresponding CF to address water-use related environmental impacts within LCA and water footprinting. Additionally, the relevance of thermal emissions in US power production has to be assessed in order to communicate environmental tradeoffs and general learnings. We analyze (1) the fate of the thermal emissions in a river until the outflow to the sea, (2) the effect of the thermal emissions in the river, and (3) the results of applying the fate and effect factors together with other CFs to determine the contribution of thermal emissions from coal and gas power plants to overall impacts on ecosystem quality in a spatially explicit LCA or water footprint study.

\section{Methods}

\subsection{Case study}

In this work, we analyze water-related impacts due from electricity generation from the latest build coal and natural gas plants $(\sim 500 \mathrm{MW})$ in the USA. In addition to thermal impacts, we also consider freshwater eutrophication, freshwater ecotoxicity, and freshwater acidification impacts (which are degradative impacts) and water consumptive effects. The functional unit used is $1 \mathrm{kWh}$ of power production. Details on these power plants and their supply chains are provided in the Supplementary Material.

\subsection{Impact of US coal and gas power production}

For testing the relevance of heat release in power production, we analyzed life cycle impacts per kWh electricity delivered from state-of-the-art gas and coal power production in the USA. For this purpose, data from the NEEDS project on state-of-the-art production (Bauer et al. 2008) is updated with ecoinvent 2.2 data (ecoinvent 2010) including the updated life cycle inventories and emissions for the supply chain. Additionally, the cooling system was modeled explicitly in order to distinguish between once-through cooling vs. cooling tower systems. We balanced the heat emissions and water consumption separately for these technologies. The minor heat emission of power plants operating with a cooling tower in our model is mainly caused by treatment of the blowdown and is a conservative estimate. Inventory for coal was adjusted to US conditions, separating the origins and chemical composition of coal in the different electricity networks of the USA (North American Electric Reliability Corporation (NERC)), based on typical coal sourcing patterns. Details are provided in the Supplementary Material.

We extended the research on assessing the impacts of thermal release from a specific nuclear power plant in Switzerland (Verones et al. 2010). Based on this study, we derived a generic fate model for the US power generation case studies by (1) creating a 0.5 arc degree grid model ( $\sim 50-\mathrm{km}$ resolution) that includes data on relevant water body temperatures, river discharge, river width, flow velocity, and distance to sea. The effect model that characterizes the impact of elevated temperatures on aquatic ecosystems (Verones et al. 2010) was used and adjusted to two different climatic zones.

Thermal emissions to freshwater have highly non-linear effects. Therefore, we assessed both the amount of heat energy released as well as the heat concentration in the river (i.e., the temperature). The fate factor describes the temperature change in the system (a volume of water) during the residence time of an emission (heat). As there is no decay for heat, only transfers to other environmental compartments (soil, groundwater, and air in our case) need to be modeled. Verones et al. (2010) show that steep temperature gradient changes are mainly relevant within a few kilometers from the point of emission, since additional water mixing at farther distances leads to dilution of the heat and small temperature changes. We divided the river into separate sections and modeled the residence time of the excess energy in the river stretch, accounting for losses to air along the distance traveled to the sea (EAWAG 1997) 
and neglecting exchanges with the sediment. This simplification led to a two-step approach: the development/calculation of (1) non-linear, temperature-based factors for local fate $\left(\mathrm{FF}_{\text {local }, i}\right)$ and effect $\left(\mathrm{EF}_{\text {local }, i}\right)$ in the model cell of heat release $i$ and (2) energy-based factors for fate $\left(\mathrm{FF}_{\text {river, }, i}\right)$ and effect $\left(\mathrm{EF}_{\text {river, }, i}\right)$ downstream of the cell of heat release until the river mouth (Fig. 1). The characterization factor $\left(\mathrm{CF}_{i}\right)$ for thermal emissions in each grid cell $i$ was calculated as:

$\mathrm{CF}_{i}=\underbrace{\mathrm{FF}_{\text {local }, i} \times \mathrm{EF}_{\text {local }, i}}_{\mathrm{CF}_{\text {local }, i}}+\underbrace{\mathrm{FF}_{\text {river }, i} \times \mathrm{EF}_{\text {river }, i}}_{\mathrm{CF}_{\text {river }, i}}$

$\mathrm{CF}_{\text {local }, i}$ is the factor summarizing fate and effect in the grid cell of thermal emission and needs to be calculated as a function of the emission rate, while $\mathrm{CF}_{\text {river }, i}$ is a linear combination of $\mathrm{FF}_{\text {river }, i}$ and $\mathrm{EF}_{\text {river }, i}$ for downstream effects.

\subsection{Fate factor on local level}

The local fate factor $\left(\mathrm{FF}_{\text {local }, i}\right)$ of the heat release grid cell must include the water flow $(Q$, based on Fekete et al. 2002 and shown in Fig. S1, Electronic Supplementary Material) to calculate the excess temperature after mixing $\left(d T_{i}\right)$ :

$d T_{i}=\frac{E_{\text {cooling }}}{Q_{i} \times \rho \times c_{p, \text { water }}} \quad ; \quad E_{\text {cooling }}=\left[\frac{M J}{s}\right] ; \quad Q_{i}=\left[\frac{m^{3}}{s}\right]$
$\rho=1.00 \frac{M g}{m^{3}} ; \quad c_{p, \text { water }}=4.18 \frac{J}{g K}$

We calculated the impacts based on the heat emission rate from cooling $\left(E_{\text {cooling }}\right)$ for 500 -MW coal and gas power plants with thermal efficiencies of 45 and $57.5 \%$, respectively, as

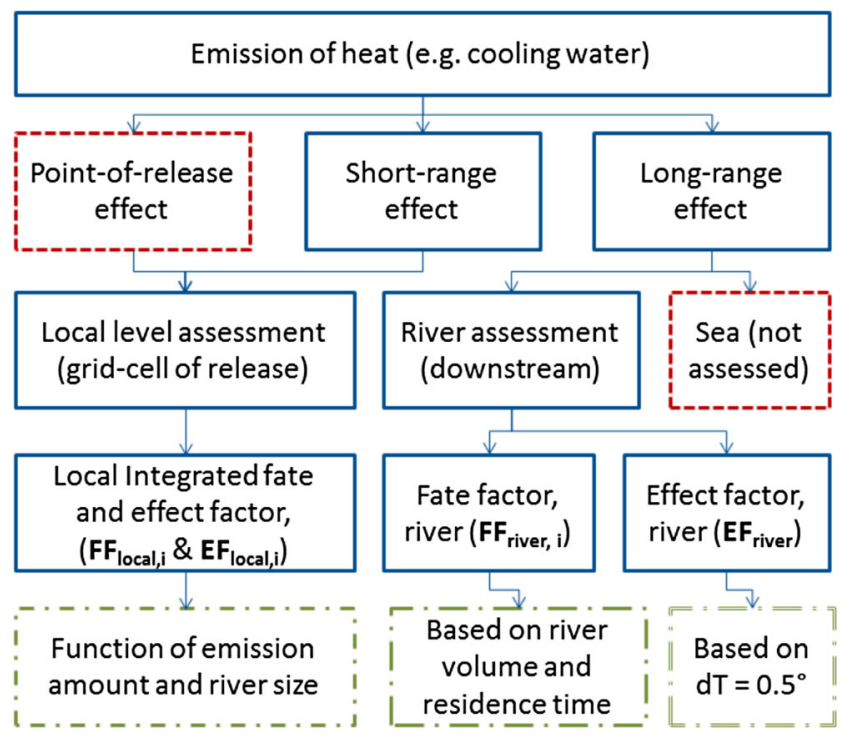

Fig. 1 Overview of the approach used in this study. Blue boxes are model components, red dashed boxes are omitted elements, and green dashed boxes indicate the model inputs described in the Supplementary Material. The residence time $\tau_{\text {res }, i}$ is calculated for each grid cell by dividing the average river travel distance within a 0.5 arc degree cell $(\sim 50 \mathrm{~km}$ as described in the Supplementary Material) by the flow velocity $\left(v_{i}\right) . v_{i}$ is calculated as a function of $Q_{i}$ based on an empirical equation (Allen et al. 1994):

$$
\begin{aligned}
& v_{i}=1.067 \times Q_{i}^{0.1035} \quad ; \quad v_{i}=\left[\frac{m}{s}\right] ; \quad Q_{i}=\left[\frac{m^{3}}{s}\right] \\
& \tau_{\text {res }}=\frac{5 \times 10^{4} m}{v_{i}} ; \quad \tau_{\text {res }}=[s] ; \quad v_{i}=\left[\frac{m}{s}\right]
\end{aligned}
$$

$\mathrm{FF}_{\text {local }, i}\left[\left(\mathrm{~K} \mathrm{~m}^{3} \mathrm{~s}\right) / \mathrm{MJ}\right]$ is consequently calculated as follows:

$$
\begin{aligned}
\mathrm{FF}_{\text {local }, i} & =d T_{i} \times \tau_{\text {res }} \times Q_{i} \times t_{\mathrm{MJ}} \\
& =\frac{E_{\text {cooling }} \times 5 \times 10^{4}}{\rho \times c_{p} \times 1.067 \times Q_{i}^{0.1035}} \times t_{\mathrm{M} \mathrm{J}}
\end{aligned}
$$

where $t_{\mathrm{MJ}}$ is the time required to emit one MJ of heat (as a function of the power plant efficiency and productivity):

$t_{\mathrm{MJ}}=\frac{1}{E_{\text {cooling }}}$

As a consequence, the fate factor is independent of the heat emission rate. However, as the effect function is non-linear, we need to assess the fate and effect in a combined way and therefore need to calculate $d T$, which is a function of $E_{\text {cooling, }}$, as an input for $\left(\mathrm{EF}_{\text {local }, i}\right)$. Hence, $E_{\text {cooling }}$ is a required inventory parameter.

\subsection{Fate factor for river}

For the long-range plume calculation (downstream of the release grid cell), the remaining part of the fate factor $\left(\mathrm{FF}_{\text {river }, i}\right)$ is calculated based on small temperature increases. We assume mixing below a critical $d T\left(0.5^{\circ} \mathrm{C}\right.$, common factor based on Verones et al. (2010)) for the long-range effect. Therefore, it is not necessary to calculate $d T$ in downstream cells as we can use the derivative of the effect function curve (marginal effect at the ambient temperature plus $0.5^{\circ} \mathrm{C}$ ).

The impact is therefore calculated through the residence time of the excess heat in the river, that is, by dividing the distance to sea by the flow velocity and accounting for heat dissipation. The distance to sea was calculated based on flow characteristics in ArcGIS (ESRI 2007) and the estimate of river flow length per grid cell (Fig. S2, Electronic Supplementary Material). The $50-\mathrm{km}$ travel distance in the release cell was deducted from the total distance to sea, as it is addressed in the short-range impacts.

The residence time $\left(\tau_{\text {res, river }, i}\right)$ of the river water from the point of release $i$ to the sea was calculated by dividing the distance to sea $\left(x_{\text {sea }}\right)$ by $v_{i}$. Lakes and other types of storage 
such as dams have not been included in the analysis, which is a simplification in the approach. In lakes, stratification leads to a mixture of temperature that is very complex, and the heat exchange due to increased surface area is different from rivers, which are at the focus of this research. The average heat remaining in the system until reaching the sea is calculated by applying the equilibrium temperature approach for rivers (EAWAG 1997, Deas and Lowney 2000):

$x_{a}=\frac{Q \times \rho \times c_{p}}{b \times A_{T}}=\frac{v \times d \times \rho \times c_{p}}{A_{T}}$

where $x_{a}[\mathrm{~m}]$ is the exchange distance after which the heat content remaining in the river is at $37 \%\left(=e^{-1}\right)$ of the initial release, $b[\mathrm{~m}]$ is the mean river width, $d[\mathrm{~m}]$ the mean river depth, and $A_{T}\left[\mathrm{~W} /\left(\mathrm{m}^{2} \mathrm{~K}\right)\right]$ the heat exchange rate. Based on our literature review (Supplementary Material), we chose an $A_{T}$ of $30 \mathrm{~W} /\left(\mathrm{m}^{2} \mathrm{~K}\right)$. We replaced $Q / b$ by $v^{*} d$, where $d$ was taken to be $5 \mathrm{~m}$ based on Verones et al. (2010) and USEtox (Rosenbaum et al. 2008); we then tested the sensitivity of the results for depths of 2 and $12.5 \mathrm{~m}$.

We were also able to calculate the heat dissipation at any distance $x$ from the point of heat release and quantify explicitly the energy left in the water at distance $x$ (Heat river $_{\text {rer }}$ ). Consequently, the heat remaining in the water at the river mouth is calculated as:

Heat $_{\text {river }}=\exp \left(\frac{x \times A_{T}}{\mathrm{~d} \times c_{p} \times v \times \rho}\right) ;$ Heat $_{\text {river, sea }}=\exp \left(\frac{x_{\text {sea }} \times A_{T}}{\mathrm{~d} \times c_{p} \times v \times \rho}\right)$

The average energy content factor for the volume of freshwater from the point of release until the sea $\left(\mathrm{Heat}_{\mathrm{river}, \mathrm{AVG}, i}\right)$ is the integral of Heat ${ }_{\text {river }}$ from the point of emission $(x=0)$ to sea $\left(x=x_{\mathrm{sea}, i}\right)$, divided by the distance $x_{\mathrm{sea}, i}$ :

$$
\begin{aligned}
& \text { Heat }_{\text {river }, \mathrm{AVG}, i}=\frac{\int_{0}^{x_{\mathrm{se}, i}} \text { Heat }_{\text {river }}}{x_{\mathrm{sea}, i}} \\
& =\frac{\left(-\frac{d \times c_{p} \times v \times \rho}{A_{T}}\right)\left(\exp \left(-\frac{x_{\mathrm{sea}, i} \times A_{T}}{d \times c_{p} \times v \times \rho}-1\right)\right.}{x_{\text {sea }, i}}
\end{aligned}
$$

Consequently, the fate of heat emission in the river $\left(\mathrm{FF}_{\text {river }, i}\right.$ $\left.\left[\left(\mathrm{K} \mathrm{m}^{3} \mathrm{~s}\right) / \mathrm{MJ}\right]\right)$ can be calculated as:

$\mathrm{FF}_{\text {river }, i}=\frac{t_{\text {res, river }, i}}{c_{p} \times \rho} \times$ Heat $_{\text {river }, \mathrm{AVG}, i}$

\subsection{Effect factor}

The effects were determined by taking into account the ambient river temperature, the temperature rise of the river water after heat release into the river $(d T)$, and the effect function, which is established with temperature tolerance intervals of different species (TTI) as explained below. Based on the method by Verones et al. (2010) and considering temperature curves in the USA, effects during the 3 months of highest water temperature (July, August, and September) were assumed to cover 30-70\% of annual impacts (that is, $50 \%$ impact during $25 \%$ of the year). Therefore, the EF calculated for these months $\left(\mathrm{EF}_{\text {peak season }}\right)$ were estimated to be double the annual average impact of heat releases $\left(\mathrm{EF}_{\text {annual }}\right)$.

\subsection{Ambient river temperatures}

River temperature is a critical environmental parameter, which is not available with high spatial coverage. We retrieved water temperature measurement data from 1907 stations for the US rivers (USGS 2011) (locations are shown in Fig. S5, Electronic Supplementary Material). The locations have been plotted on a map, and by applying the kriging method in the ArcGIS (ESRI 2007) software, temperature data was interpolated over the entire USA. Kriging also provides uncertainty estimates as shown in shown in Fig. S5 (Electronic Supplementary Material). Since the water temperature measurements are not well distributed over the USA, we additionally used water temperature estimates based on generic water/ air temperature ratios to improve data quality. A map of air temperatures in July (WorldClim 2011) $\left(T_{\text {air,Jul }}\right)$, presented in the Supplementary Material (Fig. S6, Electronic Supplementary Material), is linked to the average water temperatures for July-September $\left(T_{\text {water,Jul-Sep }}\left[{ }^{\circ} \mathrm{C}\right]\right)$. Through regression analysis, a model including uncertainties was derived:

$T_{\text {water, Jul-Sep }, i}=0.919 \times T_{\text {air }, \mathrm{Jul}, i}+0.551^{\circ} \mathrm{C}$

Results from kriging and air temperature regression were combined based on their uncertainty information in each grid cell to estimate an average value which represents the median value of the combined cumulative distribution function for the water temperature of July to September $\left(T_{\text {water,peak season }}\left[{ }^{\circ} \mathrm{C}\right]\right)$. The river temperature in each grid cell was calculated as a weighted sum of two temperature estimates: temperature calculated by interpolating the estimates from measurement stations (with an average weighting factor of $62 \%$ ) and a water temperature derived based on air temperature estimates (with an average weighting factor of $38 \%$ ). Details are presented in the Supplementary Material.

\subsection{Heat effect curve}

The effect of increased river temperature on the ecosystem was assessed based on the temperature tolerance interval (TTI) of aquatic species (including fish, molluscs, meduzosa, 
crustacean, and annelida) provided in the background data of de Vries et al. (2008) and Verones et al. (2010). TTI is the temperature increase at which $50 \%$ of the assessed species survive and is a function of the ambient water temperature. Using average TTI $\left(\mu_{\mathrm{TTI}, r}\right)$ and its standard deviation $\left(\sigma_{\mathrm{TTI}, r}\right)$ of the species pool in each climate region $r$, we built a species sensitivity distribution curve $\left(\mathrm{SSD}_{r}\right)$ following a normal temperature-response function. $\sigma_{\mathrm{TTI}, r}$ was set to $5{ }^{\circ} \mathrm{C}$ based on de Vries et al. (2008). This curve was used to calculate the effects in the grid cell of release $\left(\mathrm{EF}_{\text {local }, i}\right)$ considering the difference of potentially disappeared fraction of species $\left(\mathrm{PDF}_{r}\right)$ at ambient water temperature $T_{i}$ and temperature with

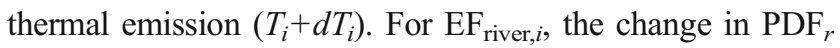
due to marginal temperature changes was calculated as:

$\frac{\mathrm{dPDF}_{r}}{d T}=\frac{-\mu_{\mathrm{TTI}, r}}{\delta_{\mathrm{TTI}, r} \times \sqrt{2 \pi}} \times \exp \left(-\frac{1}{2}\left(\frac{-\mu_{\mathrm{TTI}, r}}{\delta_{\mathrm{TTI}, r}}\right)^{2}\right)$

$\mu_{\mathrm{TTI}, r}$ is a function of water temperature $T_{i}$ : based on regression coefficients $\mu_{a, r}$ and $\mu_{b, r}$ :

$\mu_{\mathrm{TTI}, r}=\mu_{a, r} \times T_{i}+\mu_{b, r}$

Species sensitivities (TTI) are reported for subtropical and temperate climates (de Vries et al. 2008). However, this classification might not reflect situation at the edge of a climate zone, and therefore, we applied a function for mixed climates (using all species) in addition to temperate and tropical regions. For sensitivity analysis, we also built a PDF curve with the average of the three specific curves. Tropical and temperate PDF curves were allocated to watershed and grid cells based on climate zones (Fig. S7, Electronic Supplementary Material).

\subsection{Combining different freshwater ecosystem impacts in LCA}

While power production is mainly assessed by its global warming potential, water-related impacts might play a significant role in the profile of environmental impacts. Besides environmental impacts of cooling water release, we also consider effects of emissions and water consumption on freshwater ecosystems in order to analyze trade-offs and to identify hotspots including those in the supply chain. We combined state-of-the-art LCIA methods (JRC 2011): we employed ReCiPe (Goedkoop et al. 2009) for eutrophication and USEtox (Rosenbaum et al. 2008) for ecotoxicity. For water consumption, we used the method from Pfister et al. (2009), which is spatially explicit on a watershed level. We also developed NERC-specific CF for comparing power production of different US electricity grids. For freshwater acidification, we apply the methods of Roy et al. (2014) and IMPACT 2002+ (Humbert et al. 2012). We transform all impacts to endpoint impacts (measured in PDF $\mathrm{m}^{3}$ years) in order to compare the different impacts on aquatic ecosystems. There are a number of assumption and gaps in using this approach. We assume that emissions follow certain pathways to results in impacts to ecosystems. For instance, air emissions to surface water are assumed to be mainly due to precipitation. Modeling of the emissions is rather rough. Water consumption is assumed to be due to evaporation of water in cooling towers and evaporation of water in rivers due to elevated temperatures. We also assume that endpoints from different impact assessment methods can be compared. Some of the gaps include definition of species not same for different impact assessment methods, definition of species affected not same even within an impact assessment method for different impacts (e.g., eutrophication, ecotoxicity), and critical data is lacking in several instances.

\subsection{Conversion from midpoint to endpoint impacts}

USEtox measures the impact in comparative toxic unit (CTU) which is equivalent to "PAF $\mathrm{m}^{3}$ years." We converted PAF (potentially affected fraction of species) into PDF by applying a factor of 0.3 based on the literature (Goedkoop et al. 2009; Goedkoop and Spriensma 2001) as described in the Supplementary Material. The conversion from eutrophication impacts measured as kilogram phosphorus $(\mathrm{P})$ equivalents were transformed to endpoints by the factor 56.2 $\mathrm{PDF} \mathrm{m}^{3}$ years $/ \mathrm{kg}$ P, based on ReCiPe. Water consumption and freshwater acidification impacts were available at endpoint level (PDF $\mathrm{m}^{2}$ years) and need to be transposed from area to volumes of impacts. Based on five different approaches, we arrived at a conversion of $6.25 \mathrm{PDF}^{3}$ years/ PDF $\mathrm{m}^{2}$ years, as explained in the Electronic Supplementary Material.

\section{Results}

\subsection{Fate factor}

The fate factor for the release cell is a function of the runoff and is proportional to $Q^{0.1035}$ (Eq. (5)). If $Q$ is 10 times lower, $\mathrm{FF}_{\text {local }, i}$ is $27 \%$ higher since the flow speed is lower.

For $\mathrm{FF}_{\text {river, }, i}$, the distance to sea is the main influencing parameter as it determines the residence time in the freshwater ecosystem. The average residence time downstream of the point of heat release $\left(\tau_{\text {res,river }}\right)$ was found to be 8 days, while for some areas, it was more than 50 days (see Table S5, Electronic Supplementary Material).

Another important parameter is heat dissipation along the river, which is sensitive to river depth. The scenarios with 2and $12.5-\mathrm{m}$ river depth showed substantial differences compared to the initial assumption of $5 \mathrm{~m}$ (Figs. S8-9, Electronic 
Fig. 2 PDF curve of the river temperature for different climate zones (median and percentile of one and two standard deviations are depicted in the table for different climate functions)

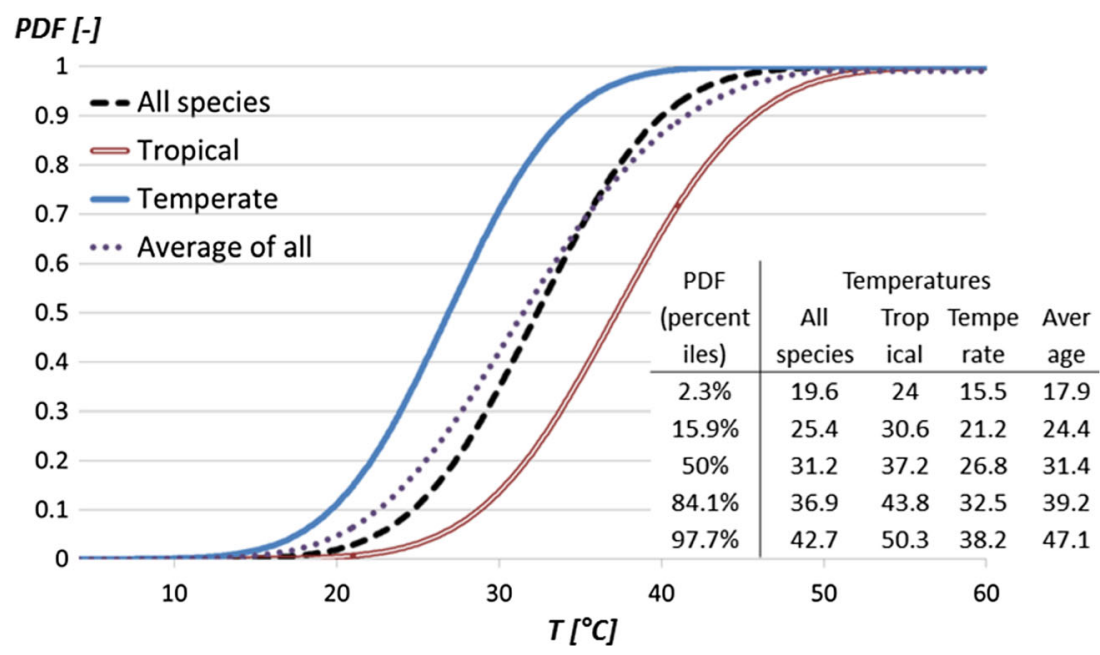

Supplementary Material). Based on assessment of all grid cells in the USA, the average heat share discharged to sea (Heat ${ }_{\text {river,sea }}$ ) is $70 \%$ for $5 \mathrm{~m}, 59 \%$ for $2 \mathrm{~m}$, and $83 \%$ for $12.5-\mathrm{m}$ river depth scenarios, respectively.

\subsection{Effect factor}

The modeled average ambient river temperature for the summer months is presented in Fig. S10 (Electronic Supplementary Material) and follows the pattern of the climate zones (Fig. S7, Electronic Supplementary Material), except for the mountainous regions in the Western USA.

The different PDF curves and selected percentiles are presented in Fig. 2. A map of resulting $\mathrm{CF}_{\text {local }, i}$ is presented in Fig. 3, for a 500-MW state-of-the art coal plant with oncethough cooling system (3.9 MJ heat emission per kWh electricity produced). Figure 3 also shows the $\mathrm{CF}$ for downstream impacts as well as the total impact $\left(\mathrm{CF}_{i}\right)$ together with a coefficient of variation $(\mathrm{CV})$ indicating the difference in the results when applying different PDF functions on each grid cell as explained above. The main variance is observed in coastal areas, where non-marginal (short-range) changes play a relevant role in the CF. Overall, the CV is rather low (below 1). The median ratio between the max and $\min \mathrm{CF}_{\text {local }, i}$ based on different PDF in each grid cell is 5.3. For local impacts, this can be significant. Non-marginal effects are also assessed by the comparison of 500- and 50-MW coal power plants. In most cases, the CF of a 50-MW plant is not significantly different than $\mathrm{CF}$ of a $500-\mathrm{MW}$ plant.

The contribution of $\mathrm{CF}_{\text {local }, i}$ and $\mathrm{CF}_{\text {river }, i}$ to total $\mathrm{CF}_{i}$ largely depends on the location and distance from the sea (see Electronic Supplementary Material), as well as the heat emission rate. On US average, $\mathrm{CF}_{\text {local }, i}$ accounts for $29 \%$ of the impact.

\subsection{Variability of CF}

Less than $5 \%$ of all values are below $1.0 \mathrm{E}-05 \mathrm{PDF} \mathrm{m}^{3}$ years/ $\mathrm{kWh}$ coal power and less than $0.1 \%$ above $1.0 \mathrm{E}-03$. Hence, a suggested value of $1.0 \mathrm{E}-04 \mathrm{PDF} \mathrm{m}^{3}$ years $/ \mathrm{kWh}(2.5 \mathrm{E}-05$ PDF $\mathrm{m}^{3}$ years/MJ emitted heat) would account for $>95 \%$ of all US values within one order of magnitude. The variability is shown in Fig. S11 (Electronic Supplementary Material). Grid cells close to the sea show typically lower CF. The CFs between two points, one around $700 \mathrm{~km}$ from the sea and the other very close to the sea, differ on average by an order of magnitude. Using the factors from Verones et al. (2011) for nuclear power in Switzerland and adjusting for thermal efficiencies results in $9.0 \mathrm{E}-05 \mathrm{PDF} \mathrm{m}^{3}$ years $/ \mathrm{kWh}$ coal power, which is matching the US average impact.

\subsection{Water footprint of US power production}

The water footprint assessment within a LCA framework indicates relatively low contribution from thermal emissions to overall freshwater ecosystem quality impacts on US average power produced (Table 1). Moreover, the relative impacts due to thermal emissions from cooling tower compared to oncethrough cooling systems turn out not to be the most pressing issue for the US average, since, according to the outcomes of this work, water consumption impacts are more important than heat releases. Coal power is consistently higher in freshwater ecosystem quality impacts since it has higher emissions

Fig. 3 Total freshwater ecosystem quality impact of heat release per kWh electricity produced with once-through cooling for the 500-MW coal power plant modeled in this project in peak months. a Within the grid cell to which the heated cooling water is released $\left(\mathrm{CF}_{\text {local }, i}\right), \mathbf{b}$ effects downstream of the release grid cell $\left(\mathrm{CF}_{\text {river, }, i}\right)$, $\mathbf{c}$ total impact $\left(\mathrm{CF}_{\text {total }, i}\right)$, and $\mathbf{d}$ coefficient of variation $(\mathrm{CV})$ of the total impact $\left(\mathrm{CF}_{\text {total }, i}\right)$ applying the four different PDF curves (for different climates) 

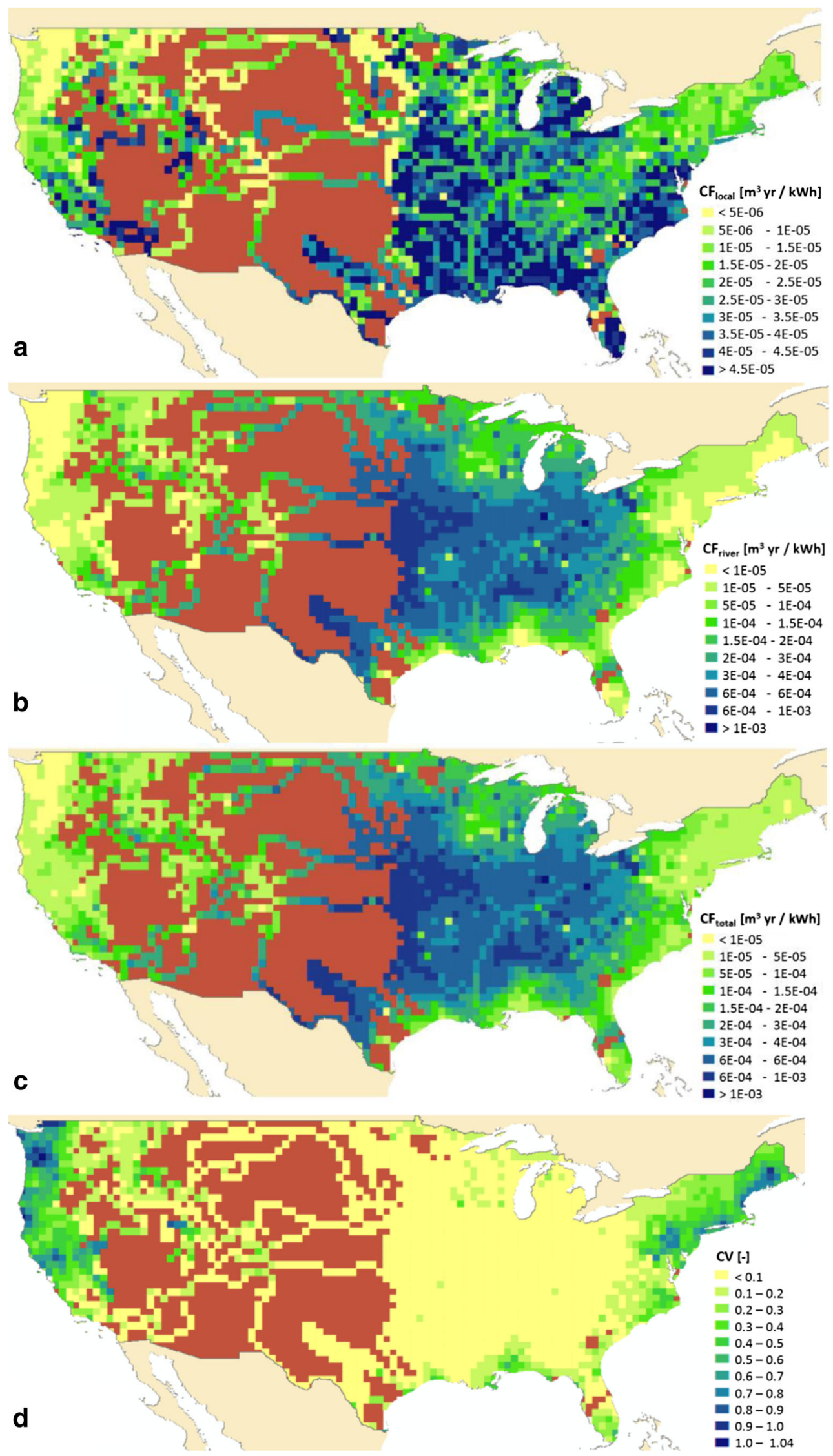
Table 1 Comparison of endpoint water impacts (normalized by coal freshwater ecotoxicity impacts) between gas- and coal-based power generation

\begin{tabular}{llllll}
\hline & \multicolumn{2}{c}{ US natural gas electricity } & & US coal electricity \\
\cline { 2 - 3 } & $\begin{array}{l}\text { Once-through } \\
\text { cooling }\end{array}$ & $\begin{array}{l}\text { Cooling } \\
\text { tower }\end{array}$ & & $\begin{array}{l}\text { Once-through } \\
\text { cooling }\end{array}$ & $\begin{array}{l}\text { Cooling } \\
\text { tower }\end{array}$ \\
\hline $\begin{array}{c}\text { Freshwater } \\
\text { eutrophication }\end{array}$ & $3.2 \mathrm{E}-03$ & $3.2 \mathrm{E}-03$ & 0.33 & 0.33 \\
$\begin{array}{c}\text { Freshwater } \\
\text { ecotoxicity }\end{array}$ & $2.8 \mathrm{E}-02$ & $2.8 \mathrm{E}-02$ & 1.00 & 1.00 \\
$\begin{array}{c}\text { Water } \\
\text { consumption }\end{array}$ & $1.1 \mathrm{E}-02$ & $2.0 \mathrm{E}-02$ & $1.8 \mathrm{E}-02$ & $3.2 \mathrm{E}-02$ \\
$\begin{array}{c}\text { Freshwater heat } \\
\text { releases }\end{array}$ & $1.3 \mathrm{E}-03$ & $2.7 \mathrm{E}-07$ & $2.2 \mathrm{E}-03$ & $4.6 \mathrm{E}-07$ \\
\hline
\end{tabular}

leading to freshwater toxicity and eutrophication and also a lower thermal efficiency, which results in higher heat emissions and water consumption per $\mathrm{kWh}$. Freshwater acidification is not integrated into the results due to the high discrepancy of the two existing methods in quantifying ecosystem quality impacts (the results differ by more than a factor 400), which is shown and discussed in detail in the SI. Based on the method of Roy et al. (2014), this impact category would dominate the aggregated freshwater ecosystem quality impacts for gas and be a major contributor for coal power, while based on the IMPACT 2002+ method (Humbert et al. 2012), its relevance would be low. However, NGCC has based on both methods $\sim 4$ times higher acidification impacts, since the coal power plant features flue-gas desulfurization. The acidification of NGCC is caused during the natural gas production (untreated "sour gas" combustion in gas turbines), which might be overestimated as further discussed in the SI.

\section{Discussion}

\subsection{Fate factor}

For future improvements in the fate assessment, better hydrological models for the river flow are required, also including lakes and storage processes. Furthermore, we suggest using a higher spatial resolution in order to improve the level of detail in river flows, since we are currently assuming power plants at the main river section (e.g., not at a tributary) in each $0.5^{\circ}$ grid cell. We did not specifically model residence times or river conditions in the downstream cells but propagated the residence time and dissipation based on values from the release point. Since the energy dissipation was generally limited to $17-41 \%$ of heat influx into the river, the impact on the fate factor is largely limited. However, the difference caused by varying depths has a substantial impact on the heat dissipation and might especially be relevant if lakes are considered in detail. While stratification of the lakes might limit the vertical mixing within lakes, the increased residence time in lakes and large dams should be considered in future research for improving the fate model. For the release point, these simplifications and uncertainties do not affect the results. The main factor there is the ambient temperature. Neglecting the detailed mixing behavior is of minor consequence in rivers that have a significant travel distance to sea as shown by Verones et al. (2010). Furthermore, the model shows that the size of the power plant in relation to $Q$ plays a key role in the expected rise in water temperature and the related effects of the fate model. Therefore, more detailed river flow models are also required for a rigorous estimate of the temperature increase. On the other hand, $d T$ is regulated by law in several cases which may not allow large power plants at small rivers (at least not with once-through cooling). The risk of underestimating the effects is consequently limited.

\subsection{Ambient river temperature}

The river temperature estimate does not integrate effects of snow melt or steep temperature gradients in rivers in mountainous regions, since both the air temperature and the interpolated water temperature data do not account for upstream temperature effects. It therefore also does not account for effects of dams on water temperature or the relevance of base flow, which can mitigate temperature fluctuations. Inclusion of such characteristics might improve the accuracy but is a research area in its own. Moreover, kriging could specifically be performed on the sub-watershed level using digital elevation models and other geographic features to interpolate measured water temperatures.

\subsection{PDF function}

Climate-specific PDF functions are important and greatly influence heat release impacts close to the river mouth (Fig. $3 \mathrm{~d}$ ). Since the PDF function is based on a single study and is valid only for two climates, further analysis might be required for global modeling, as well as for areas at the border of temperate/sub-tropical regions. Additionally, there are many different climate classifications that cannot always be unambiguously matched. Finally, the effects of the standard deviation of TTI for different species $\left(\sigma_{\mathrm{TTI}}\left[{ }^{\circ} \mathrm{C}\right]\right)$ are neglected in our model due to the limitation in data availability. However, $\sigma_{\mathrm{TTI}}$ is significant when low temperatures are involved (a high $\sigma_{\mathrm{TTI}}$ results in higher $\mathrm{CF}$ for temperatures around $15-20{ }^{\circ} \mathrm{C}$ and in lower $\mathrm{CF}$ for temperatures around $30^{\circ} \mathrm{C}$ ).

Additionally, it may be useful to couple effects with other environmental stressors, since already stressed ecosystems (e.g., due to pollution) might have a stronger reaction to heat increase. At the same time, the same loss of species might be 
attributed to two stressors, which could lead to double counting of effects.

\subsection{Peak-season based assessment}

The heat impact model represents impacts on peak temperature season (July-September). By assuming $\mathrm{CF}_{\text {annual }}$ to be $50 \%$ of the peak $\mathrm{CF}$, we introduce an uncertainty on an annual level of at most a factor of 2 , since the annual average is at least $25 \%$ of peak CF (that is, if all impact occurred during peak season) and at most $100 \%$ (if all seasons are equal in impacts). Therefore, we think this uncertainty may not be as significant as some other uncertainties in LCA water footprinting and should be improved once better data for heat effects is available.

\subsection{Impact on the sea}

This work focused on freshwater ecosystem impacts without accounting for thermal impacts on coastal regions or oceans. This is mainly due to lack of data, but it also goes beyond the scope of this study. Effects are mainly expected in coastal regions, where dilution might still be limited or when reefs are concerned. In many cases, large portions of heat are released to the sea, and therefore, the effect should be accounted for in future research. As a conservative simplification, one could assume that heat released to sea has similar impacts on the sea ecosystems as heat release to freshwater has on freshwater ecosystems.

\subsection{Array of freshwater ecosystem impacts}

As shown in detail in the Electronic Supplementary Material, the aggregation of different environmental impacts contains many assumptions and leads to large uncertainties. The conversion from area to volume impacts, for instance, leads to a high uncertainty, since different approaches result in a range of conversion factors from 0.7 to $50 \mathrm{~m}^{3} \mathrm{~m}^{-2}$. A more important consideration is that the conceptual setups of the models for water consumption and emissions are completely different, and also the models of emission rely on very diverse species groups to test and quantify the effects. Therefore, while they help to identify differences in orders of magnitude, aggregated results on endpoint-level in PDF $\mathrm{m}^{3}$ years are to be considered with caution. A new approach for assessing ecosystem quality impacts suggests quantification of global species-equivalent losses instead of a PDF-volume approach (Verones et al. 2013; Tendall et al. 2014), which could help create a more robust aggregation of different impact categories in the future.

The assessment of coal and gas power plants revealed important information about emissions contributing to the environmental effects. Toxic emissions are especially relevant in coal production, and these characterization factors have large uncertainty, especially those assessing long-term emissions. Some impact assessment methods even suggest excluding long-term effects, which is in-line with disregarding global warming effects after, for example, 100 years of emission. Eutrophication impacts also have relatively high associated uncertainties. The differences between Appalachian and Wyoming coal, described in the Electronic Supplementary Material, are not very significant considering the uncertainties in the impact assessment step. Freshwater acidification impacts have only been addressed recently, and the two published methods are not consistent in the magnitude of CF. This shows the need for future research in this topic for a complete water footprint assessment.

For water consumption and thermal emissions, the regional differences are relevant. The average ecosystem impact for the different US electricity grids (NERC) can differ by an order of magnitude. On average, cooling towers seem to have higher impacts than once-through cooling, while in specific cases, thermal emissions might be worse.

\section{Conclusions}

This study showed that thermal effects can be calculated on a spatially explicit level and revealed research gaps. The main focus should be on improving hydrological and thermal modeling for the fate factor and increasing robustness of the PDF function for the effect calculation. Compared to Verones et al. (2010), our approach requires less input data, but still providing satisfying data is a main challenge. More geographic regions need to be covered in order to facilitate a global assessment.

Acknowledgments The authors thank Catherine Raptis, Ronnie Juraske, Danielle Tendall, Francesca Verones, Stefanie Hellweg, and Mark Huijbregts for their helpful inputs and discussions and ExxonMobil Research and Engineering for partially funding this research project. The views expressed in this paper are solely those of the authors.

\section{References}

Allen PM, Arnold JC, Byars BW (1994) Downstream channel geometry for use in planning-level models. JAWRA J Am Water Resour Assoc 30:663-671

Bauer CHT, Dones R, Mayer-Spohn O, Blesl M (2008) New Energy Externalities Developments for Sustainability (NEEDS), Deliverable $n^{\circ} 7.2$ - RS 1a "Final report on technical data, costs, and life cycle inventories of advanced fossil power generation systems"

de Vries P, Tamis JE, Murk AJ, Smit MGD (2008) Development and application of a species sensitivity distribution for temperatureinduced mortality in the aquatic environment. Environ Toxicol Chem 27:2591-2598 
Deas ML, Lowney CL (2000) Water temperature modeling reviewCentral Valley. California Water and Environmental Modeling Forum

EAWAG (1997) Auswirkungen des Kernkraftwerkes Mühleberg auf den Wärmehaushalt der Aare. GBL, EAWAG, Dübendorf

ecoinvent Centre (2010) ecoinvent data v2.2. http://www.ecoinvent.org. Accessed $20 \mathrm{Feb} 2012$

ESRI (2007) ArcGIS 9.2

Fekete BM, Vörösmarty CJ, Grabs W (2002) High-resolution fields of global runoff combining observed river discharge and simulated water balances. Glob Biogeochem Cycles 16:15-11-15-10

Finkbeiner M (2009) Carbon footprinting - opportunities and threats. Int J Life Cycle Assess 14:91-94

Goedkoop M, Spriensma R (2001) The Eco-indicator 99: a damage oriented method for life cycle impact assessment: methodology report. Publikatiereeks produktenbeleid; nr. 36A, vol 3rd edition. Ministerie van Volkshiusvesting, Ruimtelijke Ordening en Milieubeheer, Den Haag

Goedkoop M, Heijungs R, Huijbregts M, De Schryver A, Struijs J, van Zelm R (2009) ReCiPe 2008 - a life cycle impact assessment method which comprises harmonised category indicators at the midpoint and the endpoint level. Available at http://cia.wik.is

Humbert S, De Schryver A, Bengoa X, Margni M, Jolliet O (2012) IMPA CT 2002+: user guide draft for version Q2.21 (version adapted by Quantis). Available at: http://www.quantis-intl.com/pdf/ IMPACT2002 UserGuide for vQ2.21.pdf

ISO (2006) ISO 14044: environmental management-life cycle assessment-requirements and guidelines. International Organization for Standardization, Geneva

ISO (2013) ISO 14067: Greenhouse gases - carbon footprint of products-requirements and guidelines for quantification and communication

ISO (2014) ISO 14046 Environmental management—water footprint— principles, requirements and guidelines

JRC (2011) International Reference Life Cycle Data System (ILCD) Handbook - recommendations for life cycle impact assessment in the European context, 1st edn. European Commission-Joint Research Centre - Institute for Environment and Sustainability, Luxemburg
Kounina A et al (2013) Review of methods addressing freshwater use in life cycle inventory and impact assessment. Int J Life Cycle Assess 18:707-721

Miara A, Vörösmarty CJ, Stewart RJ, Wollheim WM, Rosenzweig B (2013) Riverine ecosystem services and the thermoelectric sector: strategic issues facing the Northeastern United States. Environ Res Lett 8:025017

Pfister S, Koehler A, Hellweg S (2009) Assessing the environmental impacts of freshwater consumption in LCA. Environ Sci Technol 43:4098-4104

Rosenbaum RK et al (2008) USEtox-the UNEP-SETAC toxicity model: recommended characterisation factors for human toxicity and freshwater ecotoxicity in life cycle impact assessment. Int $\mathrm{J}$ Life Cycle Assess 13:532-546

Roy P-O, Deschênes L, Margni M (2014) Uncertainty and spatial variability in characterization factors for aquatic acidification at the global scale. Int J Life Cycle Assess 19(4):882-890

Tendall DM, Hellweg S, Pfister S, Huijbregts MAJ, Gaillard G (2014) Impacts of river water consumption on aquatic biodiversity in life cycle assessment - a proposed method, and a case study for Europe. Environ Sci Technol 48(6):3236-3244

USGS Surface-Water Data for the Nation (2011) http://waterdata.usgs. gov/nwis/sw. Accessed 11 Sept 2011

van Vliet MTH, Yearsley JR, Franssen WHP, Ludwig F, Haddeland I, Lettenmaier DP, Kabat P (2012) Coupled daily streamflow and water temperature modelling in large river basins. Hydrol Earth Syst Sci 16:4303-4321

Verones F, Hanafiah MM, Pfister S, Huijbregts MAJ, Pelletier GJ, Koehler A (2010) Characterization factors for thermal pollution in freshwater aquatic environments. Environ Sci Technol 44:9364-9369

Verones F, Mohd Hanafiah M, Pfister S, Huijbregts MAJ, Pelletier GJ, Koehler A (2011) Correction to characterization factors for thermal pollution in freshwater aquatic environments. Environ Sci Technol 45:7608

Verones F, Saner D, Pfister S, Baisero D, Rondinini C, Hellweg S (2013) Effects of consumptive water use on biodiversity in wetlands of international importance. Environ Sci Technol 47:12248-12257

WorldClim (2011) Global climate data; data for current conditions ( 1950-2000). http://www.worldclim.org/current. Accessed 6 Au g 2011 